\title{
Development and Characterization of New Microsatellite Markers for Perilla frutescens (L.) Britton
}

\author{
Kyu Jin Sa1, Su Eun Lim¹, Ik-Young Choi ${ }^{2}$, Kyong-Cheul Park ${ }^{2}$, Ju Kyong Lee ${ }^{{ }^{*}}$ \\ ${ }^{1}$ Department of Applied Plant Sciences, College of Agriculture and Life Sciences, Kangwon National University, Chuncheon, Korea \\ ${ }^{2}$ Department of Agriculture and Life Industry, Kangwon National University, Chuncheon, Korea \\ Email: ^jukyonglee@kangwon.ac.kr
}

How to cite this paper: Sa, K.J., Lim, S.E., Choi, I.-Y., Park, K.-C. and Lee, J.K. (2019) Development and Characterization of New Microsatellite Markers for Perilla frutescens (L.) Britton. American Journal of Plant Sciences, 10, 1623-1630.

https://doi.org/10.4236/ajps.2019.109115

Received: February 16, 2019

Accepted: September 21, 2019

Published: September 24, 2019

Copyright $\odot 2019$ by author(s) and Scientific Research Publishing Inc. This work is licensed under the Creative Commons Attribution International License (CC BY 4.0).

http://creativecommons.org/licenses/by/4.0/

\begin{abstract}
Based on RNA sequences using transcriptome analysis, 37 new simple sequence repeat (SSR) primer sets were developed for Perilla species. These new SSR markers were applied to analyze the genetic diversity among 15 accessions of Perilla species. A total of 182 alleles were confirmed in 37 loci, with an average of 4.9 alleles per locus and from 2 to 9 alleles per locus. The MAF (major allele frequency) per locus varied from 0.200 to 0.733 , with an average of 0.463 . The gene diversity (GD) ranged from 0.391 to 0.853 , with an average of 0.670 . The average polymorphic information content (PIC) was 0.624 , ranging from 0.315 to 0.838 . The new SSR markers of Perilla species reported in this study may provide potential markers to analyze the genetic diversity and genetic relationships of Perilla species. In addition, new Perilla SSR markers developed from transcriptome analysis can be useful for the identification of cultivars, conservation of Perilla germplasm resources, and genetic mapping and designating of important genes/QTLs for future Perilla crop breeding programs.
\end{abstract}

\section{Keywords}

Perilla frutescens, Oil Crop, Vegetable Crop, Genetic Diversity, Microsatellites, RNA-Seq

\section{Introduction}

Perilla frutescens (L.) Britton is widely cultivated in East Asia. There are two varieties based on the uses and morphology, $P$. frutescens var. frutescens and var. crispa. Generally, var. frutescens is used as an oil crop (ren in Chinese, dlggae in Korean and egoma in Japanese), whereas var. crispa is used as a vegetable crop 
or Chinese medicine (zisu in Chinese, cha-jo-ki in Korean and shiso in Japanese) [1] [2] [3]. Today, P. frutescens var. frutescens and var. crispa are extensively cultivated and used in Korea and Japan [2] [3] [4]. Var. frutescens is used as both a leafy vegetable and an oil crop in Korea. In contrast, var. crispa is used for vegetables or pickles, using the leaves in Japan, and is also used for Chinese medicine in China [2] [3] [5]. In East Asia, the wild species of these two varieties of Perilla crop are unknown but weedy plants of two cultivated types of $P$. frutescens have been identified [1] [2] [3]. In East Asia, the weedy plants naturally grow in wastelands, roadsides, around farming fields or farmhouses [2] [3] [5] [6]. The two cultivated types of var. frutescens and crispa in East Asia have several distinguishing morphological characters including the seed size, stem and leaf color, and plant fragrance. The weedy type of var. frutescens has a same stem and leaf color and fragrance as cultivated var. frutescens but its seeds are smaller and harder than those of cultivated var. frutescens [2] [7]. The weedy type of var. crispa is occasionally recognized and used as cultivated var. crispa by farmers because of their morphological similarities [2] [3].

Information on the genetic diversity and genetic relationships among Perilla crop and their weedy types is very important for successful Perilla crop breeding programs, the use of the germplasm resources and conservation. In previous studies, RAPD (random amplified polymorphic DNA), AFLP (amplified fragment length polymorphism), and SSR (simple sequence repeat) analyses showed that the two weedy types of Perilla crop were each grouped with the two cultivated types of var. frutescens and var. crispa [1] [5] [8] [9] [10]. Although these studies were performed to distinguish cultivated types of var. frutescens and crispa and their weedy types at the DNA level, they did not present a clear classification for these two Perilla varieties and their weedy types. Among many DNA molecular markers, SSRs are very abundant in eukaryotic genomes and show a highly variable number of repeats among individuals in a given population [11]. SSRs are often selected for genetic studies such as genetic diversity and relationship analyses because they have advantages such as high reproducibility, polymorphisms, abundance, and codominance in plant genomes [11] [12]. Our previous study successfully isolated SSRs for Perilla crop [13] [14] [15] and analyzed Perilla accessions collected from various regions [9] [14] [16] [17] [18]. However, the number of SSR markers for clear classification is still lacking.

In our previous study, we obtained 15,991 SSR loci from transcriptome sequencing by RNA-seq in one cultivated type (PF98095) of $P$. frutescens var. frutescens [19]. In this study, we successfully developed SSR primers from Perilla species, and these novel additional SSR markers can be used to analyze the genetic diversity and genetic relationships and to perform QTL mapping among two cultivated types of Perilla crop and their weedy types.

\section{Materials and Methods}

\subsection{Plant Materials and DNA Extraction}

This study used 15 accessions including the cultivated type of var. frutescens, cul- 
tivated type of var. crispa and weedy type of var. frutescens to evaluate polymorphisms and identify new SSR markers. Total DNA was extracted from the leaf tissues of a representative individual plant for each accession following the Plant DNAzol Reagent protocol (GibcoBRL Inc., Grand Island, NY, USA).

\subsection{SSR Marker Development}

To construct the transcriptome reference set in a previous study [19], de novo assembly of the PF98095 RNA-seq data was performed using Trinity software. The raw reads from NGS sequencing with a Phred quality score of at least 20 and read length of at least $50 \mathrm{bp}$ of HiSeq 2000 data were filtered before assembly. A Perl script MISA tool (https://pgrc.ipk-gatersleben.de/misa) was used to search microsatellite sites in the assembled transcriptome sequences of PF98095. The SSRs with di-, tri-, and tetra-nucleotide repeat units were identified. Based on the SSR flanking sequences, PRIMER 3 software was employed to design the primer pairs. We searched all unigenes in the cultivated type of var. frutescens (PF98095) and detected 15,991 SSR loci. In this study, we selected 200 SSR primer sets based on the 80 di-, 60 tri- and 60 tetra-nucleotide types and the number of repeat units.

\subsection{SSR Analysis and Data Analysis}

SSR amplifications were conducted in a total volume of $20 \mu$ consisting of $20 \mathrm{ng}$ genomic DNA, $1 \times$ PCR buffer, $0.5 \mu \mathrm{M}$ of forward and reverse primers, $0.2 \mathrm{mM}$ dNTPs, and 1 unit of Taq polymerase (Biotools, Madrid, Spain). The PCR profile consisted of an initial denaturation at $95^{\circ} \mathrm{C}$ for 3 minutes followed by 36 cycles of $95^{\circ} \mathrm{C}$ for 30 seconds, $55^{\circ} \mathrm{C}$ for 30 seconds, and $72^{\circ} \mathrm{C}$ for 1 minute 30 seconds with a final extension step of 5 minutes at $72^{\circ} \mathrm{C}$. After PCR analysis, the PCR products were resolved on a QIAxcel Screengel system (QIAGEN) with the 0M700 method according to the manufacturer's protocol. The number of alleles, allele frequency, major allele frequency (MAF), gene diversity (GD), and polymorphic information content (PIC) for new SSR markers were calculated using PowerMarker 3.25 [20].

\section{Results and Discussion}

Among the selected 200 SSR primer pairs, 37 SSR primer pairs had good amplification and polymorphisms among 15 Perilla accessions (Table 1). However, the remaining 163 SSR primer pairs exhibited a monomorphic band (53) or ambiguous band pattern (33) and poor or no amplification (77) in the Perilla accessions. The new 37 SSR primer pairs were used to measure the genetic diversity index, such as the number of alleles, MAF, GD, and PIC among 15 Perilla accessions, including two cultivated types of Perilla crop and their weedy types in East Asia. 182 alleles were detected in the 15 Perilla accessions, with an average of 4.9 alleles per locus, ranging from 60 to $250 \mathrm{bp}$. The number of alleles per locus ranged from 2 (KNUPE-45 and KNUPE-57) to 9 (KNUPE-42). The MAF per locus varied 
Table 1. Characteristics of the 37 SSR loci, including the primer sequence, repeat motif, annealing temperature, allele size range, and genetic diversity index among 15 Perilla accessions.

\begin{tabular}{|c|c|c|c|c|c|c|c|c|c|}
\hline SSR loci & Forward sequence & Reverse sequence & $\begin{array}{c}\text { Repeat } \\
\text { motif }\end{array}$ & $\mathrm{T}_{\mathrm{a}}$ & $\begin{array}{l}\text { Allele size } \\
\text { (bp) }\end{array}$ & $\begin{array}{l}\text { No. of } \\
\text { alleles }\end{array}$ & MAF & GD & PIC \\
\hline KNUPF-41 & CCAAAATCTCCATGTTATTGCT & ACACACATCAGGCTTTCTCTCT & $(\mathrm{AT}) 7$ & 53 & $115-150$ & 7 & 0.467 & 0.729 & 0.704 \\
\hline KNUPF-42 & CGAATTCAATAGGGAAAAATGA & AGACTCAAATCATAGGAGTTTACGA & $(\mathrm{AT}) 7$ & 53 & $140-165$ & 9 & 0.267 & 0.853 & 0.838 \\
\hline KNUPF-43 & GTCAAATGAAATTCACACATTTTA & GTAAATGGGAATTTTTGAGGAG & $(\mathrm{AT}) 7$ & 51 & $145-155$ & 6 & 0.467 & 0.720 & 0.690 \\
\hline KNUPF-44 & ATCTCCACAGATTTCACTCCTG & AATTGATTTCGTTTTACGGAGA & $(\mathrm{AT}) 7$ & 53 & $155-165$ & 6 & 0.533 & 0.667 & 0.637 \\
\hline KNUPF-45 & AGACGTTGTGTACAAATTGACG & TCTGCACTCAAATATACAAGGC & $(\mathrm{AT}) 7$ & 52 & $160-165$ & 2 & 0.733 & 0.391 & 0.315 \\
\hline KNUPF-46 & AAATTTATTGGCGTGTATCGAG & TTGAATTTGCTGCAGTTGTATC & (TG)9 & 53 & $150-160$ & 4 & 0.400 & 0.720 & 0.672 \\
\hline KNUPF-47 & TCCAAAACCCTGATTCTGTAAC & AATTTGATCCATGGGATCTTC & (TG)9 & 53 & $215-225$ & 6 & 0.467 & 0.693 & 0.652 \\
\hline KNUPF-48 & TGTCCATAAATGTTCAACCAGA & TCACCTATCATTTTCCATTGTG & (AG)26 & 53 & $125-135$ & 5 & 0.333 & 0.738 & 0.692 \\
\hline KNUPF-49 & CTAGGTGTGGGTGATTTTCAAT & АААСТАССТАССАССАТТТССС & (AG) 17 & 53 & $125-135$ & 6 & 0.267 & 0.809 & 0.781 \\
\hline KNUPF-50 & TCGTGAATGAGGGTGGTG & GCTGCTATTGGCATTTCTTATG & (CT) 17 & 54 & $160-185$ & 7 & 0.267 & 0.827 & 0.804 \\
\hline KNUPF-51 & ССТССТСТАAТАСАTGTTTCTGC & TGCAGCTTCTGTTATCTTGAAA & (AG)22 & 52 & $175-185$ & 6 & 0.533 & 0.667 & 0.637 \\
\hline KNUPF-52 & AAGACTGCATCTTTCACCAACT & TTTCTTTATACACACATCGGCA & $(\mathrm{CT}) 17$ & 53 & $205-215$ & 4 & 0.600 & 0.578 & 0.531 \\
\hline KNUPF-53 & GATTCATCATTCAGCTCTCTCC & ATGACCAATGGATTAAACAAGG & (CT) 17 & 53 & $205-220$ & 7 & 0.200 & 0.827 & 0.803 \\
\hline KNUPF-54 & GCCATTTGGAGATGGAATG & ATTTCGAGACAAAAGCAACAAT & (GC)5 & 53 & $140-150$ & 4 & 0.400 & 0.711 & 0.660 \\
\hline KNUPF-55 & TGCTGTTGATGACTTGTATGGT & ATGAGATTTGGCTTCACAGAGT & $(\mathrm{AGC}) 7$ & 53 & $240-250$ & 6 & 0.333 & 0.773 & 0.740 \\
\hline KNUPF-56 & ССТATGCATCCTTTCCAAATAA & TACGAGGTTCTGCAAGAAAAAT & $(\mathrm{AGC}) 7$ & 53 & $240-245$ & 4 & 0.333 & 0.738 & 0.690 \\
\hline KNUPF-57 & AGCAGCACTCTTCTTCTTGTTC & TCTGCAGAAGTTGTAGTCGATG & $(\mathrm{ATC}) 7$ & 53 & $170-175$ & 2 & 0.533 & 0.498 & 0.374 \\
\hline KNUPF-58 & GTATATGTGTGGGAAGGTTGCT & TCAАTTTCСТCATCAAАTCAAА & (ATG)7 & 53 & $215-220$ & 3 & 0.600 & 0.551 & 0.485 \\
\hline KNUPF-59 & AATCTCGATGCCTAACAACAGT & TTCCTTGTAAATCCAGCTAAGG & (CAG)7 & 53 & $140-150$ & 4 & 0.600 & 0.578 & 0.531 \\
\hline KNUPF-60 & GCAATGGACATCTGTGAGAGTA & AATTGTGGTAATCATAGGGCAG & $(\mathrm{CAG}) 7$ & 53 & $180-185$ & 4 & 0.667 & 0.507 & 0.462 \\
\hline KNUPF-61 & GGGATACCCAAATTTCTACCAT & TCATGAAAAATCCAAACATTCA & $(\mathrm{CAG}) 7$ & 53 & $220-225$ & 4 & 0.600 & 0.560 & 0.501 \\
\hline KNUPF-62 & ССАТССТТСТTGTTCAАСТСАТ & AATGTTGATGAGGAGACGTTTT & $(\mathrm{CAT}) 7$ & 53 & $185-190$ & 4 & 0.467 & 0.667 & 0.610 \\
\hline KNUPF-63 & AATGTATTTTCGGCAGAGAGAA & CGGAGTTCAGAGCAAAGATTAT & $(\mathrm{CGT}) 7$ & 53 & $145-150$ & 6 & 0.400 & 0.711 & 0.666 \\
\hline KNUPF-64 & TTTGAAGGTCTAACAGTGTCTGAA & AACTGAGATTTTGACCAAGCAG & (CTA)7 & 53 & $230-240$ & 5 & 0.400 & 0.720 & 0.674 \\
\hline KNUPF-65 & TAAATCAAGTTGGTAAGCATGG & CAGAAAACTACCTCCATATCGC & (CTA) 7 & 52 & $240-245$ & 3 & 0.400 & 0.658 & 0.584 \\
\hline KNUPF-66 & GTCCTTTTGTCAAGAGACTGCT & ССТТСТСССТTTGAAGAAAAGT & $(\mathrm{GCT}) 7$ & 53 & $235-245$ & 4 & 0.467 & 0.613 & 0.537 \\
\hline KNUPF-67 & ATTGATTCTCTATCAACCTGGC & CTCATCATCGGATCAACCTAGT & $(\mathrm{GCT}) 7$ & 53 & $225-240$ & 7 & 0.467 & 0.729 & 0.704 \\
\hline KNUPF-68 & GAGTGAAATGCTCGACTTGAT & CAAGTCTCATTCTTTCCAGACC & $(\mathrm{GTA}) 7$ & 52 & $150-155$ & 4 & 0.467 & 0.676 & 0.623 \\
\hline KNUPF-69 & TCTTCTCCAAGTCATGTCTTCTT & TGGAGTGGTCGAGAGAAGTAGT & (TCA)7 & 53 & $60-65$ & 3 & 0.600 & 0.560 & 0.499 \\
\hline KNUPF-70 & GAGATCAATAGTGGCAGTGGTT & AAACTAAACCAATGGCGTAGAA & (TCG)7 & 53 & $125-135$ & 5 & 0.467 & 0.693 & 0.650 \\
\hline KNUPF-71 & GAAGAATGCATCAGTAACACGA & ATGCTGGCCAAGTAATAAGAGA & $(\mathrm{AGCT}) 4$ & 53 & $190-200$ & 6 & 0.333 & 0.791 & 0.762 \\
\hline KNUPF-72 & TAATTTGAGGGATTCCTTTCCT & CGCCACCCTTACTACTTCATAC & (TCGA) 4 & 53 & $235-245$ & 4 & 0.400 & 0.711 & 0.660 \\
\hline KNUPF-73 & ССАТTCTTCAATTCGATCAACTA & TCTGCAAATCATCCAGTTAAAA & (CTAG) 4 & 53 & $135-145$ & 3 & 0.733 & 0.427 & 0.388 \\
\hline KNUPF-74 & TTGACTGTACCAGAGCATCAAG & GGGTACACTCACAАСТCTACСАA & $(\mathrm{AAAT}) 6$ & 53 & $185-200$ & 7 & 0.467 & 0.729 & 0.704 \\
\hline KNUPF-75 & САТАТТСТСАССАССАААСТСС & GAGAAGAGAAGGAAGCAAACAA & $(\mathrm{CTTT}) 7$ & 53 & $160-180$ & 6 & 0.400 & 0.738 & 0.700 \\
\hline KNUPF-76 & AAAGTTTAGACAGCCCAACAAA & CTTAGCGTCAAGAAACAGCAG & (AGGG)6 & 53 & $210-215$ & 5 & 0.600 & 0.587 & 0.547 \\
\hline \multirow[t]{2}{*}{ KNUPF-77 } & TTTTTGGTTGCTTTTTCTTGAT & AGCAGATAAAATGTGCTGGATT & (TATG) 10 & 53 & $155-165$ & 4 & 0.467 & 0.649 & 0.586 \\
\hline & & & & & Average & 4.9 & 0.463 & 0.670 & 0.624 \\
\hline
\end{tabular}

$\mathrm{T}_{\mathrm{a}}$ : annealing temperature, MAF: major allele frequency, GD: genetic diversity, PIC: polymorphic information content. 
from 0.200 (KNUPE-53) to 0.733 (KNUPE-73), with an average of 0.463 . The GD ranged from 0.391 (KNUPE-45) to 0.853 (KNUPE-42), with an average of 0.670. The average PIC was 0.624 , ranging from 0.315 (KNUPE-45) to 0.838 (KNUPE-42) (Table 1).

The analysis of the three groups of Perilla accessions (cultivated and weedy types of var. frutescens and cultivated type of var. crispa) using the 37 SSR primers showed that the average number of alleles ranged from 2.6 for the weedy type of var. frutescens to 3.4 for the cultivated type of var. crispa. The average GD were 0.586 and 0.461 for the cultivated and weedy types of var. frutescens, respectively, and 0.629 for the cultivated var. crispa. The average PIC were 0.524 , 0.406 and 0.565 for the cultivated and weedy types of var. frutescens and cultivated var. crispa, respectively (Table 2). Perilla crop is widely distributed and cultivated in Korea, Japan and China. This information is about the genetic diversity of Perilla may be useful for the preservation of germplasm resources in East Asia.

Table 2. Estimates of allele number, MAF, gene diversity and PIC of 37 SSR primers among cultivated and weedy types of Perilla.

\begin{tabular}{|c|c|c|c|c|c|c|c|c|c|c|c|c|}
\hline \multirow[t]{2}{*}{ SSR loci } & \multicolumn{3}{|c|}{ No. of alleles } & \multicolumn{3}{|c|}{ Major Allele Frequency } & \multicolumn{3}{|c|}{ Gene Diversity } & \multicolumn{3}{|c|}{ PIC } \\
\hline & Group1 & Group2 & Group3 & Group1 & Group2 & Group3 & Group1 & Group2 & Group3 & Group1 & Group2 & Group3 \\
\hline & $(\mathrm{n}=5)$ & $(\mathrm{n}=5)$ & $(\mathrm{n}=5)$ & $(\mathrm{n}=5)$ & $(\mathrm{n}=5)$ & $(\mathrm{n}=5)$ & $(\mathrm{n}=5)$ & $(\mathrm{n}=5)$ & $(\mathrm{n}=5)$ & $(\mathrm{n}=5)$ & $(\mathrm{n}=5)$ & $(\mathrm{n}=5)$ \\
\hline KNUPF-41 & 3 & 4 & 4 & 0.600 & 0.400 & 0.400 & 0.560 & 0.720 & 0.720 & 0.499 & 0.672 & 0.672 \\
\hline KNUPF-42 & 4 & 4 & 5 & 0.400 & 0.400 & 0.200 & 0.720 & 0.720 & 0.800 & 0.672 & 0.672 & 0.768 \\
\hline KNUPF-43 & 4 & 1 & 4 & 0.400 & 1.000 & 0.400 & 0.720 & 0.000 & 0.720 & 0.672 & 0.000 & 0.672 \\
\hline KNUPF-44 & 3 & 2 & 4 & 0.600 & 0.800 & 0.400 & 0.560 & 0.320 & 0.720 & 0.499 & 0.269 & 0.672 \\
\hline KNUPF-45 & 1 & 2 & 2 & 1.000 & 0.800 & 0.600 & 0.000 & 0.320 & 0.480 & 0.000 & 0.269 & 0.365 \\
\hline KNUPF-46 & 3 & 3 & 3 & 0.600 & 0.400 & 0.400 & 0.560 & 0.640 & 0.640 & 0.499 & 0.563 & 0.563 \\
\hline KNUPF-47 & 4 & 2 & 4 & 0.400 & 0.600 & 0.400 & 0.720 & 0.480 & 0.720 & 0.672 & 0.365 & 0.672 \\
\hline KNUPF-48 & 4 & 4 & 2 & 0.400 & 0.400 & 0.600 & 0.720 & 0.720 & 0.480 & 0.672 & 0.672 & 0.365 \\
\hline KNUPF-49 & 4 & 4 & 3 & 0.400 & 0.400 & 0.400 & 0.720 & 0.720 & 0.640 & 0.672 & 0.672 & 0.563 \\
\hline KNUPF-50 & 5 & 3 & 5 & 0.200 & 0.400 & 0.200 & 0.800 & 0.640 & 0.800 & 0.768 & 0.563 & 0.768 \\
\hline KNUPF-51 & 3 & 2 & 4 & 0.600 & 0.800 & 0.400 & 0.560 & 0.320 & 0.720 & 0.499 & 0.269 & 0.672 \\
\hline KNUPF-52 & 2 & 2 & 4 & 0.800 & 0.800 & 0.400 & 0.320 & 0.320 & 0.720 & 0.269 & 0.269 & 0.672 \\
\hline KNUPF-53 & 4 & 5 & 5 & 0.400 & 0.200 & 0.200 & 0.720 & 0.800 & 0.800 & 0.672 & 0.768 & 0.768 \\
\hline KNUPF-54 & 3 & 3 & 4 & 0.400 & 0.600 & 0.400 & 0.640 & 0.560 & 0.720 & 0.563 & 0.499 & 0.672 \\
\hline KNUPF-55 & 3 & 3 & 3 & 0.400 & 0.400 & 0.600 & 0.640 & 0.640 & 0.560 & 0.563 & 0.563 & 0.499 \\
\hline KNUPF-56 & 3 & 3 & 3 & 0.600 & 0.600 & 0.400 & 0.560 & 0.560 & 0.640 & 0.499 & 0.499 & 0.563 \\
\hline KNUPF-57 & 2 & 2 & 2 & 0.600 & 0.800 & 0.800 & 0.480 & 0.320 & 0.320 & 0.365 & 0.269 & 0.269 \\
\hline KNUPF-58 & 3 & 1 & 3 & 0.600 & 1.000 & 0.600 & 0.560 & 0.000 & 0.560 & 0.499 & 0.000 & 0.499 \\
\hline KNUPF-59 & 3 & 3 & 2 & 0.600 & 0.600 & 0.600 & 0.560 & 0.560 & 0.480 & 0.499 & 0.499 & 0.365 \\
\hline KNUPF-60 & 2 & 2 & 3 & 0.800 & 0.800 & 0.400 & 0.320 & 0.320 & 0.640 & 0.269 & 0.269 & 0.563 \\
\hline
\end{tabular}




\begin{tabular}{|c|c|c|c|c|c|c|c|c|c|c|c|c|}
\hline KNUPF-61 & 3 & 1 & 3 & 0.400 & 1.000 & 0.400 & 0.640 & 0.000 & 0.640 & 0.563 & 0.000 & 0.563 \\
\hline KNUPF-62 & 3 & 2 & 2 & 0.600 & 0.800 & 0.600 & 0.560 & 0.320 & 0.480 & 0.499 & 0.269 & 0.365 \\
\hline KNUPF-63 & 3 & 2 & 4 & 0.600 & 0.800 & 0.400 & 0.560 & 0.320 & 0.720 & 0.499 & 0.269 & 0.672 \\
\hline KNUPF-64 & 2 & 4 & 2 & 0.600 & 0.400 & 0.600 & 0.480 & 0.720 & 0.480 & 0.365 & 0.672 & 0.365 \\
\hline KNUPF-65 & 3 & 2 & 3 & 0.400 & 0.800 & 0.400 & 0.640 & 0.320 & 0.640 & 0.563 & 0.269 & 0.563 \\
\hline KNUPF-66 & 3 & 2 & 3 & 0.400 & 0.600 & 0.600 & 0.640 & 0.480 & 0.560 & 0.563 & 0.365 & 0.499 \\
\hline KNUPF-67 & 3 & 3 & 5 & 0.600 & 0.600 & 0.200 & 0.560 & 0.560 & 0.800 & 0.499 & 0.499 & 0.768 \\
\hline KNUPF-68 & 4 & 3 & 3 & 0.400 & 0.600 & 0.600 & 0.720 & 0.560 & 0.560 & 0.672 & 0.499 & 0.499 \\
\hline KNUPF-69 & 2 & 2 & 3 & 0.600 & 0.600 & 0.600 & 0.480 & 0.480 & 0.560 & 0.365 & 0.365 & 0.499 \\
\hline KNUPF-70 & 3 & 4 & 2 & 0.600 & 0.400 & 0.600 & 0.560 & 0.720 & 0.480 & 0.499 & 0.672 & 0.365 \\
\hline KNUPF-71 & 4 & 3 & 4 & 0.400 & 0.600 & 0.400 & 0.720 & 0.560 & 0.720 & 0.672 & 0.499 & 0.672 \\
\hline KNUPF-72 & 3 & 3 & 3 & 0.600 & 0.600 & 0.600 & 0.560 & 0.560 & 0.560 & 0.499 & 0.499 & 0.499 \\
\hline KNUPF-73 & 3 & 1 & 3 & 0.600 & 1.000 & 0.600 & 0.560 & 0.000 & 0.560 & 0.499 & 0.000 & 0.499 \\
\hline KNUPF-74 & 4 & 2 & 4 & 0.400 & 0.800 & 0.400 & 0.720 & 0.320 & 0.720 & 0.672 & 0.269 & 0.672 \\
\hline KNUPF-75 & 3 & 3 & 5 & 0.400 & 0.600 & 0.200 & 0.640 & 0.560 & 0.800 & 0.563 & 0.499 & 0.768 \\
\hline KNUPF-76 & 3 & 2 & 3 & 0.400 & 0.800 & 0.600 & 0.640 & 0.320 & 0.560 & 0.563 & 0.269 & 0.499 \\
\hline KNUPF-77 & 3 & 3 & 3 & 0.600 & 0.600 & 0.600 & 0.560 & 0.560 & 0.560 & 0.499 & 0.499 & 0.499 \\
\hline Average & 3.1 & 2.6 & 3.4 & 0.524 & 0.643 & 0.465 & 0.586 & 0.461 & 0.629 & 0.524 & 0.406 & 0.565 \\
\hline
\end{tabular}

Group 1: Cultivated var. frutescens, Group 2: Weedy var. frutescens, Group 3: Cultivated var. crispa.

Our study results using new Perilla SSR primers validate the proposal that the weedy types of Perilla species are the key taxon in understanding the origin of the two cultivated types of var. frutescens and var. crispa. The new Perilla SSR primers described in this study should facilitate confirmation of the genetic diversity and could be used for the identification of cultivars, conservation of $\mathrm{Pe}$ rilla germplasm resources, and genetic mapping and designating of important genes/QTLs for Perilla crop breeding programs.

\section{Acknowledgements}

This study was supported by the Basic Science Research Program through the National Research Foundation of Korea (NRF) funded by the Ministry of Education, Science, and Technology (\#2016R1D1A1B01006461).

\section{Conflicts of Interest}

The authors declare no conflicts of interest regarding the publication of this paper.

\section{References}

[1] Nitta, M. and Ohnishi, O. (1999) Genetic Relationships among Two Perilla Crops, Shiso and Egoma, and the Weedy Type Revealed by RAPD Markers. The Japanese 
Journal of Genetics, 74, 43-48. https://doi.org/10.1266/ggs.74.43

[2] Lee, J.K. and Ohnishi, O. (2001) Geographic Differentiation of Morphological Characters among Perilla Crops and Their Weedy Types in East Asia. Breeding Science, 51, 247-255. https://doi.org/10.1270/jsbbs.51.247

[3] Nitta, M., Lee, J.K. and Ohnishi, O. (2003) Asian Perilla Crops and Their Weedy Forms: Their Cultivation, Utilization and Genetic Relationships. Economic Botany, 57, 245-253. https://doi.org/10.1663/0013-0001(2003)057[0245:APCATW]2.0.CO;2

[4] Nitta, M. (2001) Origin of Perilla Crops and Their Weedy Type. PhD Diss., Kyoto University, Kyoto, 78.

[5] Lee, J.K., Nitta, M., Kim, N.S., Park, C.H., Yoon, K.M., Shin, Y.B. and Ohnishi, O. (2002) Genetic Diversity of Perilla and Related Weedy Types in Korea Determined by AFLP Analyses. Crop Science, 42, 2161-2166. https://doi.org/10.2135/cropsci2002.2161

[6] Nitta, M., Lee, J.K., Kang, C.W., Katsuta, M., Yasumoto, S., Liu, D., Nagamine, T. and Ohnishi, O. (2005) The Distribution of Perilla Species. Genetic Resources and Crop Evolution, 52, 797-8044. https://doi.org/10.1007/s10722-003-6017-5

[7] Sa, K.J., Kim, J.A. and Lee, J.K. (2012) Comparison of Seed Characteristics between the Cultivated and the Weedy Types of Perilla Species. Horticulture Environment and Biotechnology, 53, 310-315. https://doi.org/10.1007/s13580-012-0031-5

[8] Lee, J.K. and Ohnishi, O. (2003) Genetic Relationships among Cultivated Types of Perilla frutescens and Their Weedy Types in East Asia Revealed by AFLP Markers. Genetic Resources and Crop Evolution, 50, 65-74. https://doi.org/10.1023/A:1022951002271

[9] Sa, K.J., Choi, S.H., Ueno, M., Park, K.C., Park, Y.J., Ma, K.H. and Lee, J.K. (2013) Identification of Genetic Variations of Cultivated and Weedy Types of Perilla Species in Korea and Japan Using Morphological and SSR Markers. Genes \& Genomics, 35, 649-659. https://doi.org/10.1007/s13258-013-0117-1

[10] Sa, K.J., Choi, S.H., Ueno, M. and Lee, J.K. (2015) Genetic Diversity and Population Structure in Cultivated and Weedy Types of Perilla in East Asia and Other Countries as Revealed by SSR Markers. Horticulture Environment and Biotechnology, 56, 524-534. https://doi.org/10.1007/s13580-015-0039-8

[11] Park, Y.J., Lee, J.K. and Kim, N.S. (2009) Simple Sequence Repeat Polymorphisms (SSRPs) for Evaluation of Molecular Diversity and Germplasm Classification of Minor Crops. Molecules, 14, 4546-4569. https://doi.org/10.3390/molecules14114546

[12] Powell, W., Morgante, M., Andre, C., Hanafey, M., Vogel, J., Tingey, S. and Rafalski, A. (1996) The Comparison of RFLP, RAPD, AFLP and SSR (SSR) Markers for Germplasm Analysis. Molecular Breeding, 2, 225-238. https://doi.org/10.1007/BF00564200

[13] Kwon, S.J., Lee, J.K., Kim, N.S., Yu, J.W., Dixit, A., Cho, E.G. and Park, Y.J. (2005) Isolation and Characterization of SSR Markers in Perilla frutescens Britt. Molecular Ecology Notes, 5, 454-456. https://doi.org/10.1111/j.1471-8286.2005.00901.X

[14] Park, Y.J., Dixit, A., Ma, K.H., Lee, J.K., Lee, M.H., Chung, C.S., Nitta, M., Okuno, K., Kim, T.S., Cho, E.G. and Rao, V.R. (2008) Evaluation of Genetic Diversity and Relationships within an On-Farm Collection of Perilla frutescens (L.) Britt. Using SSR Markers. Genetic Resources and Crop Evolution, 55, 523-535. https://doi.org/10.1007/s10722-007-9258-x

[15] Sa, K.J., Choi, I.Y., Park, K.C. and Lee, J.K. (2018) Genetic Diversity and Population Structure among Accessions of Perilla frutescens (L.) Britton in East Asia Using New Developed Microsatellite Markers. Genes \& Genomics, 40, 1319-1329. https://doi.org/10.1007/s13258-018-0727-8 
[16] Lee, J.K. and Kim, N.S. (2007) Genetic Diversity and Relationships of Cultivated and Weedy Types of Perilla frutescens Collected from East Asia Revealed by SSR Markers. Korean Journal of Breeding Science, 39, 491-499.

[17] Lee, J.K., Kwon, S.J., Park, B.J., Kim, M.J., Park, Y.J., Ma, K.H., Lee, S.Y. and Kim, J.H. (2007) Analysis of Genetic Diversity and Relationships of Cultivated and Weedy Types of Perilla frutescens Collected from Korea by Using Microsatellite Markers. Korean Journal of Genetics, 29, 81-89. https://doi.org/10.7848/ksgpc.2011.29.1.81

[18] Ma, S.J., Sa, K.J., Hong, T.K. and Lee, J.K. (2017) Genetic Diversity and Population Structure Analysis in Perilla frutescens from Northern Areas of China Based on Simple Sequence Repeats. Genetics and Molecular Research, 16, gmr16039746. https://doi.org/10.4238/gmr16039746

[19] Tong, W., Kwon, S.J., Lee, J.S., Choi, I.Y., Park, Y.J., Choi, S.H., Sa, K.J., Kim, B.W. and Lee, J.K. (2015) Gene Set by De Novo Assembly of Perilla Species and Expression Profiling between $P$. frutescens (L.) var. frutescens and var. crispa. Gene, 559, 155-163. https://doi.org/10.1016/j.gene.2015.01.028

[20] Liu, K. and Muse, S.V. (2005) Power Marker: An Integrated Analysis Environment for Genetic Marker Analysis. Bioinformatics, 21, 2128-2129.

https://doi.org/10.1093/bioinformatics/bti282 